\title{
Lactate Dehydrogenase Level as an Early Predictor of Transient Tachypnea of the Newborn Duration and Complications
}

\author{
Mada Osefori, MD, Leen Jamel Doya, MD*, Bana Nezha, MD and Adnan Dayoub \\ Department of Pediatrics, Faculty of Medicine, Tishreen University Hospital, Lattakia, Syria
}

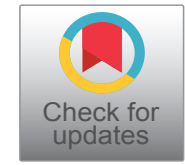

*Corresponding author: Leen Jamel Doya, MD, Department of Pediatrics, Faculty of Medicine, Tishreen University Hospital, Lattakia, Syria, Tel: 0963992856983

\begin{abstract}
Background: Transient tachypnea of the newborn (TTNB) is a common cause of respiratory distress in the postnatal period. It is rarely associated with serious complications that need intensive care. Prediction of the complications during the first hours of hospitalization is very difficult, so the purpose of the current study is to investigate the relationship between lactate dehydrogenase (LDH) level in blood and the course of Transient tachypnea of the newborn (the duration of hospitalization, and the incidence of complications).

Material and methods: In a cross-sectional study design included 120 neonates with Transient tachypnea of the newborn who had referred to the Neonatal Intensive Care Unit (NICU) at Tishreen University Hospital over 1 year period from January 2018 to January 2019. The neonates were classified according to Lactate dehydrogenase measurement as normal or high lactate dehydrogenase level in blood.
\end{abstract}

Results: The results showed that there was a significant relationship between the level of lactate dehydrogenase and the duration of hospitalization, the incidence of complications, and the frequency of complications.

Conclusions: Lactate dehydrogenase might be useful for clinicians to predict the duration of hospitalization and the incidence of complications in neonates with TTNB.

\section{Keywords}

Transient tachypnea of newborn, Lactate dehydrogenase level, The duration of hospitalization, Complications

\section{Introduction}

Transient tachypnea of the newborn (TTNB) is an important neonatal cause of respiratory distress which occurs due to delayed reabsorption of the pulmonary alveolar fluid [1]. The incidence of TTN is 5.7 per 1000 births [2]. TTN is suspected when the infant develops respiratory distress shortly after birth. Symptoms of TTNB include tachypnea (Respiratory Rate RR > 60/ $\min )$, grunting, nasal flaring, intercostal retraction, and cyanosis. The diagnose of TTN is based on the previous clinical features after excluding the other causes of tachypnea depending on the laboratory and radiological tests [3]. In TTNB, the oxygen concentration is deficient, energy is provided by the anaerobic pathway metabolism of glucose, and then pyruvate is deoxidized into lactate by lactate dehydrogenase [4]. Although TTNB is a selflimited condition in most cases, it may complicate with more serious problems (needs oxygen support or mechanical ventilation). Prediction of the complications during the first hours of hospitalization is very difficult, so the current study investigates the association between $\mathrm{LDH}$ level in blood and the course of TTNB (the duration of hospitalization, and the incidence of complications).

\section{Material and Methods}

A cross-sectional retrospective study included 120 neonates with TTNB who had been referred to the Neonatal Intensive Care Unit (NICU) at Tishreen University Hospital in Lattakia, Syria over 1 year period from January 2018 to January 2019. Patients who had pneumonia, early neonatal sepsis, meconium aspiration syndrome, asphyxia (Apgar $5 \mathrm{~min}<6$ in association with arterial $\mathrm{pH}<7.05$ or venous $\mathrm{pH}<7.17$ and base excess $\leq-10 \mathrm{mmol} / \mathrm{L}$ ), cardiac/pulmonary abnormalities, or newborns of a diabetic mother were excluded.

Clinical data include gestational age, gender, birth

Citation: Osefori M, Doya LJ, Nezha B, Dayoub A (2021) Lactate Dehydrogenase Level as an Early Predictor of Transient Tachypnea of the Newborn Duration and Complications. Int J Pediatr Res 7:075. doi. org/10.23937/2469-5769/1510075

Accepted: June 09, 2021: Published: June 11, 2021

Copyright: (c) 2021 Osefori M, et al. This is an open-access article distributed under the terms of the Creative Commons Attribution License, which permits unrestricted use, distribution, and reproduction in any medium, provided the original author and source are credited. 
pattern, Apgar score, and birth weight was obtained. A Physical examination was performed. Chest X-Ray and Laboratory data were obtained at the admission of all neonates including complete blood cells $(C B C)$, C-reactive protein (CRP), and lactate dehydrogenase (LDH). LDH was analyzed and classified according to the value LDH (290-775) U/I [5] into patients with normal or high LDH levels. The clinical course, duration of hospitalization, and the incidence of complications of patients were followed up.

All data were analyzed using the Statistical Package for Social Sciences (SPSS Version 20). Data were presented in simple measures of frequency, percentage, mean. The significance of the difference between different means (quantitative data) was tested using Student's t-test for the difference between two independent means, while different percentages (qualitative data) were tested using Pearson's Chi-square test.

\section{Results}

The study included 120 neonates with TTNB, 80

Table 1: Demographic variables of the neonates.

\begin{tabular}{|c|c|}
\hline Variables & Total neonates \\
\hline \multicolumn{2}{|l|}{ Gender } \\
\hline Male, n (\%) & $80(66.7)$ \\
\hline Female, n (\%) & $40(33.3)$ \\
\hline \multicolumn{2}{|l|}{ Mode of delivery } \\
\hline Cesarean delivery, n (\%) & $117(97.5)$ \\
\hline Vaginal birth, n (\%) & $3(2.5)$ \\
\hline \multicolumn{2}{|l|}{ Gestational age } \\
\hline 37 GW, n (\%) & $41(34.2)$ \\
\hline $38 \mathrm{GW}, \mathrm{n}(\%)$ & $47(39.2)$ \\
\hline 39 GW, n (\%) & $32(26.7)$ \\
\hline \multicolumn{2}{|c|}{ Duration of hospitalization } \\
\hline Less than 3 days, $\mathrm{n}(\%)$ & $72(60)$ \\
\hline More than 3 days, $\mathrm{n}(\%)$ & $48(40)$ \\
\hline \multicolumn{2}{|c|}{ Complication (pneumothorax) } \\
\hline No, $n(\%)$ & $108(90)$ \\
\hline Yes, n (\%) & $12(10)$ \\
\hline
\end{tabular}

GW: Gestational week.
(66.7\%) were male and 40 (33.3\%) were female with a mean birth weight of $2855 \mathrm{~g}$. Cesarean section pattern was predominant in 117 (97.5\%), gestational age more than 37 weeks was in 47 cases (39.2\%). The duration of hospitalization was less than 3 days in 72 (60\%). $12(10 \%)$ of neonates developed pneumothorax as a complication. Table 1 showed the demographic variable of the neonates.

The frequency of high LDH levels was $46.6 \%$. Comparison between high and low LDH level groups, there was a significant relationship between the high $\mathrm{LDH}$ levels and the duration of hospitalization and the complications according to Pearson's Chi-square test (Table 2).

Bycalculating the value of the regression coefficient $(R$ Square), it was 0.634 for the duration of hospitalization, which means that $63.4 \%$ of the changes in the duration of hospitalization are associated with an increase in the level of LDH (Figure 1). R Square was 0.239 for the complications that refer to $23.9 \%$ of changes in the incidence of complications are associated with the high level of LDH (Figure 2).

\section{Discussion}

Newborn care with a limited number of available places in NICU remains a major concern in developing countries. Therefore, the early prediction of the disease progression is essential for clinicians to provide adequate support. The current study supports the importance of using laboratory tests in neonates with TTNB to predict the course of TTNB.

It is well known that enzymes leak out of cells after damage induced by ischemic hypoxemia. Lactate and $\mathrm{LDH}$ are considered good predictors of asphyxia [6]. $\mathrm{LDH}$ is an enzyme that mediates the conversion of lactate to pyruvate as well as the reverse reaction. It is found in several organs and tissues such as the liver, heart, lungs, lymphatic tissues, and blood cells. When cells are damaged, LDH is released out of cells into the bloodstream which elevates its level in plasma. There are several types of LDH known as isoenzymes, which are distinguished from each other by slight differences in structure and by the organs where they exist [7]. LDH level increases in the case of hypoxia and its highest

Table 2: Comparison between high and normal LDH groups according to the duration of hospitalization and complication.

\begin{tabular}{|c|c|c|}
\hline \multirow[t]{2}{*}{ Variables } & High LDH levels & Normal LDH levels \\
\hline & $N=56$ & $N=64$ \\
\hline \multicolumn{3}{|c|}{ Duration of hospitalization } \\
\hline Less than 3 days, n (\%) & $8(6.7)$ & $64(53.3)$ \\
\hline More than 3 days, $n(\%)$ & $48(40)$ & $0(0)$ \\
\hline \multicolumn{3}{|c|}{ Complication (pneumothorax) } \\
\hline No, n (\%) & $44(36.7)$ & $64(53.3)$ \\
\hline Yes, n (\%) & $12(10)$ & $0(0)$ \\
\hline
\end{tabular}




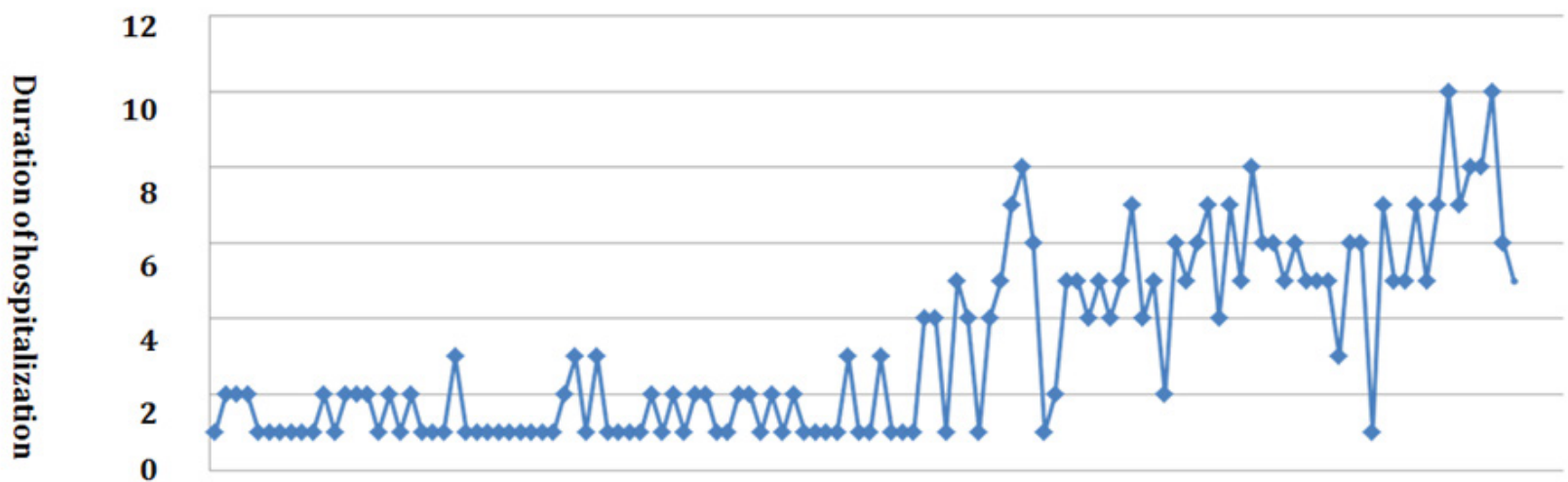

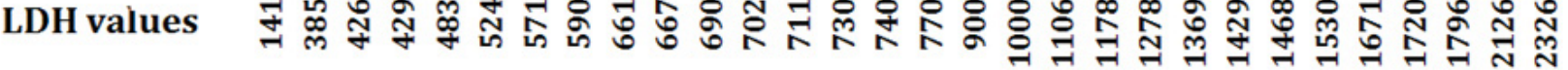

Figure 1: The association between duration of hospitalization and LDH levels.

\section{Complication}

\section{No complication}

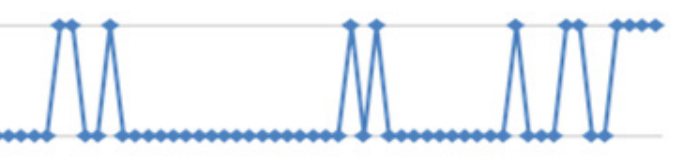

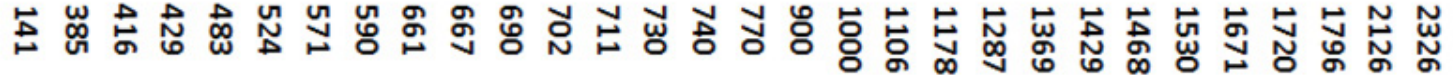

\section{LDH value}

Figure 2: The association between the incidence of complications and LDH levels.

level are within 72 hours after birth. It returns to normal within the first 10 days of life [8].

In the current study, we noticed a positive correlation between the duration of hospitalization, the incidence of complications, and the LDH level. The duration of hospitalization as well as the frequency of complication increases as the value of LDH increases. To Our knowledge, this is the first study investigating the relationship between the duration of hospitalization, the incidence of complications, and the level of LDH in TTNB neonates. The study of Ozkiraz, et al. showed a significant relationship between prolonged oxygen supplement and high LDH levels [4]. The study of Anh confirmed that plasma LDH level can be a predictive biomarkerfor the prognosis of severe conditions (early-onset neonatal sepsis, asphyxia, and respiratory distress) in newborn infants [9]. Elfarargy MS, et al. conducted that serum LAH had a beneficial role as early predictors in differentiation between TTN and RDS in neonates [10].

The lack of availability of pulmonary LDH analysis was one of the limitations of the current study. Repeated measurement of LDH was not made over time in individual subjects to investigate the correlation with the clinical course of TTNB that may be also a limitation.

\section{Conclusion}

The current study demonstrates that the level of LDH may be predictive of subsequent hospitalization duration and the incidence of complications in neonates having TTNB. This may be used as a predictive measure through which prevention can be achieved by referring the TTNB patient to the NICU before the clinical situation is worsened.

\section{Acknowledgments}

We wish to thank the medical officer, doctors in the pediatric department, and laboratory assistants in Tishreen University Hospital laboratory who worked with us in reviewing the patients and doing the laboratory analysis.

\section{Conflict of Interest Statement}

None declared.

\section{Data Availability}

We can't share patient data due to our hospital's 
privacy policy, which is concerned with maintaining patient confidentiality and refuses to publish or share data. Also, the informed consent signed by the parents to participate in the study prevents the sharing of information with the non-study researchers.

\section{Statement of Ethics}

All parents whose children were studied gave informed consent for the sharing of this research. Ethical clearance for this study was obtained from the Ethical Committee of the University of Tishreen Hospital

\section{Funding Sources}

None.

\section{Author Contributions}

The Authors developed and carried out sample collection. Literature review, the data analysis and read through the final data were done by authors.

\section{References}

1. Avery ME, Gatewood OB, Brumley G (1966) Transient tachypnea of newborn. Possible delayed resorption of fluid at birth. Am J Dis Child 111: 380-385.

2. Morrison JJ, Rennie JM, Milton PJ (1995) Neonatal respiratory morbidity and mode of delivery at term: Influence of timing of elective caesarean section. $\mathrm{Br} \mathrm{J}$ Obstet Gynaecol 102: 101-106.
3. Gomella TL, Cunningham MD, Eyal FG, Zenk KE (2013) Neonatology: Management, procedures, on call problem diseases, and drugs. ( $7^{\text {th }}$ edn), McGraw-Hill, New York, 919-925.

4. Ozkiraz S, Gokmen Z, Boke SB, Kilicdag H, Ozel D, et al. (2013) Lactate and lactate dehydrogenase in predicting the severity of transient tachypnea of the newborn. J Matern Fetal Neonatal Med 26: 1245-1248.

5. Show_Duh (2005) Laboratory refrence range levels. University of Maryland School of Medicine.

6. Karlsson M, Wiberg-Itzel E, Chakkarapani E, Blennow M, Winbladh B, et al. (2010) Lactate dehydrogenase predicts hypoxic ischaemic encephalopathy in newborn neonates: $A$ preliminary study. Acta Paediatr 99: 1139-1144.

7. Van Eerd JP, Kreutzer EK (1996) Klinische Chemievoor Analistendeel. 2: 138-139.

8. Karlsson M, Blennow M, Nemeth A, Winbladh B (2006) Dynamics of hepatic enzyme activity following birth asphyxia. Acta Paediatr 95: 1405-1411.

9. Van Anh TN, Hao TK, Hoang HH (2020) The role of plasma lactate dehydrogenase testing in the prediction of severe conditions in newborn infants: A prospective study. Research and Reports in Neonatology 10: 31-35.

10. Elfarargy MS, Al-Ashmawy GM, Abu-Risha S, Khattab H (2021) Novel predictor markers for early differentiation between transient tachypnea of newborn and respiratory distress syndrome in neonates. Int $\mathrm{J}$ Immunopathol Pharmacol 35: 20587384211000554. 